\title{
Complications of staple line and anastomoses following laparoscopic bariatric surgery
}

\author{
Gianfranco Silecchia, Angelo lossa \\ University of Rome "La Sapienza", Rome, Italy
}

\begin{abstract}
With over 600 million people being obese, and given the scientific demonstration of the advantages of surgical treatment, bariatric surgery is on the rise. The promising long-term results in terms of weight loss, and particularly in relation to comorbidities and the control/cure rate, mean that the number of procedures performed in all countries remains high. However, the risk of potentially complex or fatal complications, though small, is present and is related to the procedures per se. This review is a guide for bariatric and/or general surgeons, offering a complete overview of the pathogenesis of anastomosis and staple line following the most common laparoscopic bariatric procedures: sleeve gastrectomy, gastric bypass, and mini-gastric bypass. The review is divided according to the procedure and the complications (leak, bleeding and stenosis), and evaluates all the factors that can potentially improve or worsen the complication rate, representing a "unicum" in the present literature on bariatric surgery.
\end{abstract}

Keywords Bariatric surgery, complications, laparoscopic, staple line, prevention, leaks, stenosis, bleeding

Ann Gastroenterol 2018; 31(1): 1-9

\section{Introduction}

The number of bariatric operations performed worldwide is continuously rising. Based on the last International Federation for the Surgery of Obesity and Metabolic Disorders (IFSO) survey in 2014, a total of 579,517 procedures involving sleeve gastrectomy (SG) or the Roux-en-Y gastric bypass (RYGB), which represent the two most popular techniques (45.9 and $39.6 \%$, respectively), have been performed [1]. The worldwide mini-gastric bypass (MGB) trend has reached a plateau, with the exception of the Asia/Pacific region. The current report on the number of MGB procedures could be underestimated, since the USA and Canada did not provide any data [1].

Each operation predisposes to specific postoperative complications because of the presence of multiple sequential or crossing staple lines and anastomoses (gastro-entero;

Department of Medical-Surgical Sciences and Biotechnologies, Division of General Surgery and Bariatric Centre of Excellence, University of Rome "La Sapienza", Rome, Italy

\section{Conflict of Interest: None}

Correspondence to: Angelo Iossa MD, Department of Medico-Surgical Sciences and Biotechnologies Division of General Surgery and Bariatric Center of Excellence, "La Sapienza", University of Rome, Italy, e-mail: angelo.iossa@uniroma1.it, angelo.iossa@gmail.com

Received 31 May 2017; accepted 8 September 2017; published online 12 October 2017

DOI: https://doi.org/10.20524/aog.2017.0201 entero-entero). The most frequent postoperative complications after bariatric surgery are bleeding, leaks, and stenosis of the anastomosis. Knowledge of the clinical presentation, together with the postoperative anatomy, is crucial for the prevention, early diagnosis and proper management of those potentially life-threatening complications. The aim of this review is to evaluate the complications of the staple line and anastomoses in the most common bariatric procedures, evaluating for each the risk factors and the prevention strategies.

\section{SG: staple-line complications}

Major surgical complications, such as bleeding, leakage and gastric stenosis, occur in about $5 \%$ of cases in large series [2]. The mean incidence of leakage, which usually occurs in the upper portion of the staple line, is $2.1 \%(1.1-5.3 \%)$ [2]. Leak is the second most common cause of death after SG, with an overall reported mortality rate of $0.4 \%$ [3].

\section{Staple-line leak: pathogenesis and prevention}

Pathogenesis of leakage after SG can be attributed to mechanical or ischemic causes [4]. Many factors, either technical or patient-related, can predispose to leakage. According to Baker et al [5], stapler misfiring or direct tissue injuries are categorized as "mechanical-tissular" causes and usually appear within 2 days of surgery (early leak). The mechanical factors are usually related to the intrinsic characteristics of the long 
staple line (approx. $20 \mathrm{~cm}$ ). The phenomena of tissue creep, stress relaxation, and shear stress are dependent upon one common factor, which is time. Hence, optimal stapling should allow adequate time for tissue compression and creeping while preventing excessive tensile stress. Usually, waiting at least $15 \mathrm{sec}$ before firing helps to optimize this concept and allow adequate pre-cut compression time [5]. The choice of adequate cartridge is essential and many studies have been published on this topic, showing a great variability in the stomach wall thickness, related to the portion of the stomach (from antrum to fundus), sex, and the procedures (primary or revisional). Based on the latest evidence, proper cartridge selection among the several options offered on the market by the two major brands (Ethicon Echelon ${ }^{\text {TM }}$ Stapler-Echelon Flex $^{\text {rm }}$ Endopath $^{\oplus}$ Stapler, Ethicon Endo-Surgery, Inc., Cincinnati, OH, USA; and Covidien Endo GIA ${ }^{\text {rx }}$ Reloads with Tri-Staple ${ }^{\text {Tx }}$ TechnologyCovidien, Dublin, Ireland) is challenging in the absence of routine intraoperative measurement of gastric wall thickness. The appropriate cartridge "colors" using the Stapler-Echelon Flex $^{\mathrm{m}}$ Endopath ${ }^{\oplus}$ Stapler at the antrum, midbody, and fundus in both patient groups (male/female) seem to be black, black, and blue, respectively [6]. In contrast, with the Endo GIA ${ }^{\text {m }}$ Tri-Staple ${ }^{\mathrm{T}}$ the appropriate cartridge colors appear to be black, black, and purple respectively, although the black cartridge for the antrum with this technology is completely appropriate in only 1 of every 6 female patients [6]. Despite the evidence, many surgeons use different colored cartridges, or use the same color for the entire staple line in combination with different kinds of stapler reinforcement (suture, glue, buttress materials). In the absence of current guidelines, the only assumption is that $81 \%$ of the panel experts of the international consensus summit for SG believe that it is not appropriate to use staples with a closed height less than that of a blue load (1.5 mm open) on any part of the SG [7]. When using these devices to create a long staple line, the surgeon must search for and remove the migratory "crotch" staple [5]. Failure to notice and remove this crotch staple may result in a staple misfire.

It is strongly recommended to maintain an adequate distance from the gastroesophageal junction in order to avoid ischemic complications related to the transection of the segmental vascularization of this area, where the majority of leaks occur (Fig. 1), although the ischemic theory of leak is not so strongly confirmed by the recent literature [8].

The choice of bougie size (between 32 and $40 \mathrm{Fr}$ ) could worsen the leak rate by creating an overpressure inside the pouch. A meta-analysis of Parikh et al, including 198 leaks in 8922 patients, revealed that the risk of leak decreased with a bougie $\geq 40 \mathrm{Fr}$, with no difference in percentage excessive weight loss between a bougie $<40 \mathrm{Fr}$ and a bougie $\geq 40 \mathrm{Fr}$ up to 36 months [9]. This strong evidence supports the use of $\geq 40 \mathrm{Fr}$ bougies to decrease the leak rates, with controversial effects on weight loss [9-11].

The distance from the pylorus varies from $2-6 \mathrm{~cm}$ and is related to a variable leak rate attributed to the higher intragastric pressure obtained after antral resection. Increasing the size of the resected antrum might be associated with better short- and mid-term weight loss results, but could increase the leak rate [11-13]. Recalling that the bougie is only an inferior

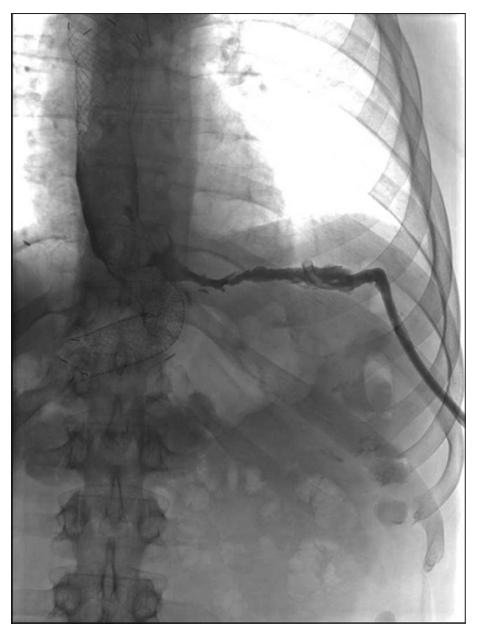

Figure 1 Sleeve gastrectomy: leak

resecting limit, the principal rule for avoiding overpressure in the sleeve is the critical orientation of the created sleeve, respecting the incisura and the staple-line orientation, together with a correct choice of bougie [4]. The creation of a gastric tube that is not cylindrical in shape results in high pressure, especially at the most proximal corner of the staple line (Laplace's Law) and thus results in a higher probability of leak in the proximal third of the tubular stomach. A spiral-shaped staple line can result in functional obstruction; in addition, stapling too close to the incisura can result in anatomical narrowing, creating a high-pressure system; both are preventable causes of leak that can potentially result in a high-pressure system [4].

The leak rate is also related to the surgical experience, as reported by Noel et al [14]. The authors analyzed their experience in two groups, Group A (first 900) and Group B (last 900 laparoscopic SG [LSG]), showing a critical decrease in leak rate from $2 \%$ to $0.2 \%$, $(\mathrm{P}=0.001)$.

Regarding staple-line reinforcement (SLR) as a leakreducing option, several tools have been proposed, including the following: oversewing, absorbable synthetic buttress material (synthetic glycolide trimethylene carbonate copolymer Gore ${ }^{\circledast}$ Seamguard ${ }^{\circledast}$ Bioabsorbable Staple Line Reinforcement), biologic cross-linked buttressing (bovine pericardium strips, Peri-strips Dry ${ }^{\circledast}$ and PSD Veritas ${ }^{\circledR}$ Baxter), biologic non-cross-linked buttressing (absorbable) (porcine small intestinal submucosa, Surgisis Biodesign ${ }^{\circledR}$ ), thrombin matrix (Floseal ${ }^{\oplus}$, Baxter Healthcare), and fibrin glue (Tisseel, Baxter Healthcare). The current high-level evidence showed that absorbable buttress materials applied on adequate cartridges appear to offer safer and more effective control of staple-line bleeding and leak (1.09\% with Gore ${ }^{\circledR}$ Seamguard $^{\oplus}[2]$ vs. $1.83 \%$ with Peri-strips Dry $\left.{ }^{\otimes}[15]\right)$ and an increased cost compared with non-reinforced staple lines, but at the same time single-center experience in a large population demonstrated excellent results using fibrin glue as SLR (0\%) [16], as well as the inverting absorbable suture (Lembert's suture) (0\%) [17]. Berger et al published the first report from the metabolic and bariatric surgery accreditation and quality improvement program (MBSAQIP), which evaluated the outcomes of 
189,477 patients who underwent SG with or without SLR [10], and demonstrated a negative effect of SLR on leak rate: $0.96 \%$ vs. $0.65 \%$ (odds ratio [OR] $1.20,95 \%$ confidence interval [CI] 1.00-1.43). Placement of drains does not facilitate the detection of leak and/or abscess and they do not appear to eliminate the reoperation rates for these complications, which usually occur after the patient's discharge [18].

A leak after SG represents a complex condition, hard to solve and potentially life threatening, with a high additional cost. Prolonged hospitalization in the ICU accounted for the majority of hospital costs (58.9\%), with a total cost of $€ 304,290$ [19].

In conclusion, based on evidence in the literature, measures for the prevention of leak include the following:

- Use a bougie size $\geq 40 \mathrm{Fr}$

- Begin the gastric transection 5-6 cm from the pylorus

- Use appropriate cartridge colors from antrum to fundus

- Perform a proper staple line

- Remove the crotch staples

- Maintain proper traction on the stomach before firing

- Stay at least $1 \mathrm{~cm}$ away from the angle of His and $1.5 \mathrm{~cm}$ from the incisura

- Reinforce the staple line (buttress, glue and Lembert's suture)

\section{Staple-line bleeding: pathogenesis and prevention}

A long stapler line is mostly responsible for postoperative bleeding in $0-20 \%$ cases, with a re-operation rate of $1.4 \%$ for major bleeding [20] (Fig. 2), while intraluminal bleeding is uncommon. Modifiable factors should be investigated and corrected before surgery. Comorbidities, such as liver disease (non-alcoholic fatty liver), coagulopathy, hypertension and super-obesity, increase the bleeding risk and should be carefully evaluated and treated preoperatively when possible [21,22]. Patients who are candidates for SG as a revisional procedure, mainly after adjustable gastric band

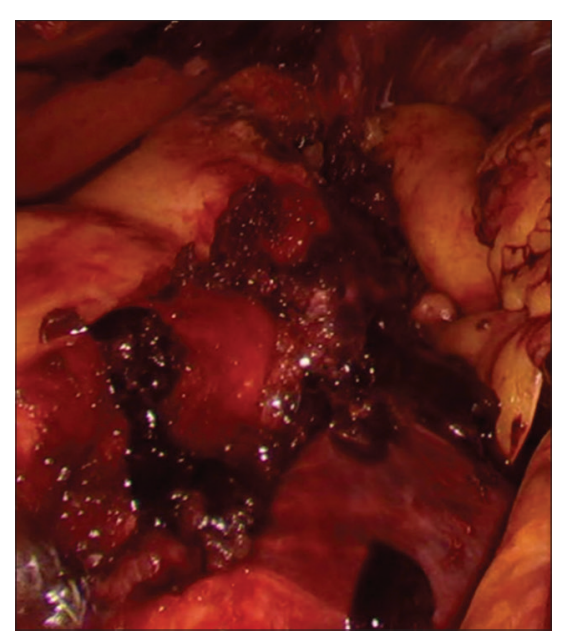

Figure 2 Sleeve gastrectomy: staple-line bleeding. Re-laparoscopy failure or complications, represent a high-risk subset. Based on a "sleeve bleed calculator" published this year [23], the authors concluded that the protective factors for hemorrhagic complications were no history of obstructive sleep apnea (OR 0.22 ; 95CI $0.05-0.94$ ) and no history of hypertension (OR 0.38; 95\%CI 0.14-1.05), while a low level of expertise in bariatric surgery (OR 2.85; 95\%CI 1.08-7.53) and no stapleline reinforcement (OR 3.34; 95\%CI 1.21-9.21) were associated with a higher risk of hemorrhagic complications. Another intraoperative bleed control protocol has been published recently by De Angelis et al; it involves an adjustment of the systolic blood pressure to $140 \mathrm{mmHg}$ and a simultaneous reduction of the pneumoperitoneum to $10 \mathrm{~mm} / \mathrm{Hg}$ in order to identify the possible silent bleeding; the authors reported a post-operative bleeding rate of $0 \%$ [24]. The SLR seems to play a central role in bleeding, as was indicated by two high-level evidence papers: in 2015, Shikora published a meta-analysis that assessed four SLR options (no reinforcement, oversewing, bovine pericardial strips, and absorbable polymer membrane), showing bleeding rates of $1.16 \%$ and $2.09 \%$ with reinforcement (bovine pericardial strips and absorbable polymer membrane, respectively) compared with $4.94 \%$ and $2.41 \%$ for the noreinforcement technique and the oversuture, respectively [15]. Recently, Berger, evaluating the outcomes of 189,477 patients undergoing LSG with or without SLR, showed a positive effect of SLR on bleed rate: $0.75 \%$ vs. $1 \%$ (OR $0.74 ; 95 \%$ CI 0.63 $0.86)$ [10]. There is evidence that using fibrin glue (bleed rate $0.3 \%)$ [16] and inverting suture $(0.1 \%)$ [17] leads to excellent results; these need to be re-evaluated in large populations and based on multicenter experience. Placement of drains does not facilitate the detection of bleeding. Furthermore, they do not seem to reduce the reoperation rates for these complications. It is possible that patients with previous laparoscopic adjustable gastric banding and intraperitoneal bleeding could benefit from placement of a drain that will remain for more than 5 days [18].

In conclusion, based on the evidence in the literature, the adequate prevention of bleeding includes the following:

- Reinforce the staple line (buttress, glue and Lembert's suture)

- Choose an adequate cartridge

- Control hemostasis with low intra-abdominal pressure and increased systolic blood pressure $(\geq 140 \mathrm{mmHg})$

\section{Staple-line stenosis: pathogenesis and prevention}

Staple-line stenosis occurs in $0.7 \%$ to $4 \%$ of patients who undergo LSG and often causes nausea, vomiting, epigastric pain and reflux; if untreated, it can lead to readmission [25]. It has been suggested that mechanical gastric can be caused by retraction of scar, oversewing of the staple line, overtraction of the greater curvature during stapling, or small hematomas or leaks that heal as scar tissue [25]. Sharp angulation or a spiral of the gastric sleeve could result from an incomplete gastric sleeve stenosis, or from other mechanisms such as asymmetrical 
lateral traction, with stapling leading to twisting of the gastric tube via a volvulus-like mechanism [25-27]. The site of stenosis is most often at the incisura angularis or gastroesophageal junction [26,28] (Fig. 3). When a stenosis occurs, it is usually one of two types: a functional one (passage of the endoscope is possible but the sleeve is twisted with various degrees of rotation, requiring the scope to be passed through the gastric lumenthe so-called helix stenosis) or a mechanical one (when the passage of the endoscope is very difficult or impossible) [26]. Stricture and kinking may be avoided by keeping a safe distance between the incisura angularis and the edge where the staples are applied. In agreement with Manos et al, we believe that left-hand stapling offers the proper direction "to respect the incisura angularis" [26]. During left-hand stapling, the device will be parallel with the lesser curvature and not perpendicular,

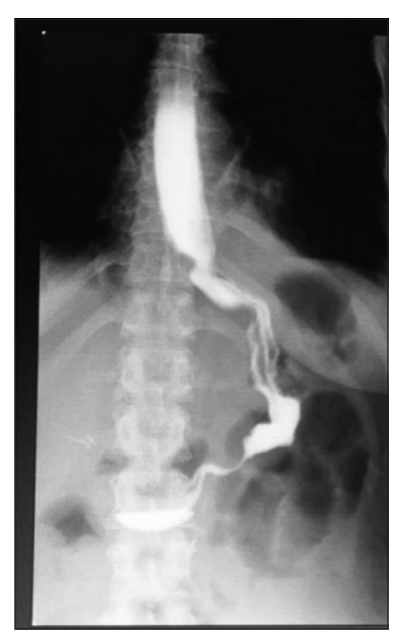

Figure 3 Sleeve gastrectomy: mid-gastric stenosis as is the case when performing right-hand stapling. Keeping the staple line straight by resecting symmetrically anterior and posterior walls of the stomach represents the main factor for avoiding staple line twisting [26].

In conclusion, in the majority of cases staple-line stenosis represents a technical error related to incorrect traction of the stomach during stapling, or an inappropriate distance from the incisura. Table 1 presents a summary of the complications.

\section{Gastric bypass: staple-line complications}

The most common anastomotic complications after RYGB are bleeding, stenosis and fistula. These complications occur predominantly at the gastrojejunal (G-J) anastomosis, with the following incidence ranges: bleeding $1-4 \%[28,29]$, stenosis $3-28 \%$ [28-30], and leaks $0.1-5.8 \%$ [28,29]. Several studies have shown the leak-associated mortality to reach $37.5-50 \%$ [28-30].

\section{Staple-line leak: pathogenesis and prevention}

The incidence of anastomotic leaks ranges from $0.1-5.8 \%[28,29]$. Patients may present with any combination of abdominal pain, persistent tachycardia, shortness of breath, fever, hypotension, and unexplained sepsis. The leaks most commonly occur at the G-J anastomosis [28,29] but can also occur at the gastric pouch stapler line, gastric remnant, or jejunojejunostomy. This is usually an early complication (most commonly within 1 week after surgery). In 2016 Varban et al [31] published a retrospective analysis of the Michigan Bariatric Surgery Collaborative, including 16,258 patients who underwent RYGB, and reported the following results: according

Table 1 Summary of staple-line complications after laparoscopic sleeve gastrectomy (SG)

\begin{tabular}{|c|c|c|c|}
\hline & Incidence & Pathogenesis & Prevention \\
\hline Leak & $2.1 \%(1.1-5.3 \%)$ & $\begin{array}{l}\text { Narrow tube }(<40 \mathrm{Fr} \text { bougie }) \text {; } \\
\text { Distance from } \mathrm{AOH}(<1 \mathrm{~cm}) \text {; } \\
\text { Twisted/stenotic tube; } \\
\text { Staple misfiring }\end{array}$ & $\begin{array}{l}\text { Bougie size } \geq 40 \mathrm{Fr} \text {; } \\
\text { Distance from the pylorus } 5-6 \mathrm{~cm} \text {; } \\
\text { Appropriate cartridge colors from antrum to fundus; } \\
\text { Straight staple line; } \\
\text { Crotch staples removal; } \\
\text { Distance from } \mathrm{AOH} \text { at least } 1 \mathrm{~cm} \text { and } 1.5 \mathrm{~cm} \text { from the } \\
\text { incisura; } \\
\text { Staple-line reinforcement (buttress, glue and Lembert's } \\
\text { suture) }\end{array}$ \\
\hline Bleeding & $0-20 \%$ & $\begin{array}{l}\text { Patient-related factors: } \\
\text { Liver disease, coagulopathy, hypertension, } \\
\text { super-obesity, revisional surgery } \\
\text { Surgeon-related factors: } \\
\text { Low level of expertise, no staple-line } \\
\text { reinforcement }\end{array}$ & $\begin{array}{l}\text { Staple line reinforcement (buttress, glue and Lembert's } \\
\text { suture); } \\
\text { Appropriate cartridge colors from antrum to fundus; } \\
\text { Bleeding check with low intra-abdominal pressure and } \\
\text { increased systolic blood pressure }(\geq 140 \mathrm{mmHg})\end{array}$ \\
\hline Stenosis & $0.7-4 \%$ & $\begin{array}{l}\text { Oversewing of the staple line; } \\
\text { Overtraction of the greater curvature during } \\
\text { stapling; } \\
\text { Small hematomas or leaks that heal as scar tissue }\end{array}$ & $\begin{array}{l}\text { Symmetric/lateral traction of the stomach during } \\
\text { stapling; } \\
\text { Distance of } 1.5 \mathrm{~cm} \text { from the incisura }\end{array}$ \\
\hline
\end{tabular}

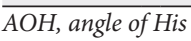


to the univariate analysis, cases with an increased blood transfusion requirement (OR 4.3; 95\%CI 1.00-1.01, $\mathrm{P}=0.0015$ ), conversions from laparoscopic to open surgery (OR 10.00; 95\%CI 1.17-85.59; $\mathrm{P}=0.0356)$, the use of buttressing material (OR 3.35; 95\%CI 1.61-6.99; $\mathrm{P}=0.0013$ ), and Covidien stapler brand (OR 2.02; 95\%CI 1.08-3.76; $\mathrm{P}=0.0268$ ) were associated with a significantly higher rate of anastomotic leak. Conversely, the use of fibrin sealant over the G-J anastomoses was associated with a significantly lower rate of leaks (OR 0.37; 95\%CI 0.17 $0.79 ; \mathrm{P}=0.0099$ ). After multivariate analysis, only the use of buttressing material continued to be associated with a higher rate of leaks (OR 8.79; 95\%CI 2.49-31.01; $\mathrm{P}=0.0007$ ), whereas the use of fibrin sealant was associated with a decrease in the likelihood of leaks (OR 0.11; 95\%CI 0.03-0.41 P=0.0013) [31]. Contrary to those results regarding fibrin sealant, Ibele et al, in a retrospective study evaluating 529 patients (429 fibrin sealant group vs. 104 no), found a leak rate of $0.9 \%$ vs. $1.9 \%$ $(\mathrm{P}=0.2)$ [32]. Furthermore, regarding SLR, Shikora et al [15], in a recent meta-analysis evaluating the advantages of SLR in gastrointestinal surgery, showed that the leak rate in gastric bypass decreased progressively using SLR, reporting the following percentages: no $\mathrm{SRL}=2.60 \%$, oversuture $=2.44 \%$, glycolide copolymer $=1.88 \%$, bovine pericardium $=1 \%$. As recently reported in a meta-analysis that compared different kind of G-J anastomosis [33], no significant differences were observed in leak and reoperation rate. Compared with circular (CSA), hand-sewn (HAS) anastomosis had a similar risk of leak (OR 1.65; 95\%CI, 0.61-4.48; $\mathrm{P}=0.33$; and reoperation (OR 0.50; 95\%CI 0.10-2.54; $\mathrm{P}=0.40)$. Compared with LSA, HSA also had a similar risk of leak (OR 1.46; 95\%CI 0.72-2.96; $\mathrm{P}=0.29$;), and reoperation (OR 1.03; 95\%CI 0.52-2.04; $\mathrm{P}=0.94$ ) (Table 2) [33].

In conclusion, leaks after RYGB are not influenced by the type of G-J anastomosis, but can be positively influenced by the use of fibrin glue.

\section{Staple-line bleeding: pathogenesis and prevention}

Bleeding usually takes place in the early postoperative course (within the first hours to days) [28]. The bleeding after RYGB can originate at one of five potential staple lines: the gastric pouch, excluded stomach, Roux limb staple line, gastrojejunostomy, and jejunojejunostomy. Staple-line bleeding occurs at the transected tissue edges or at the sites where staples penetrate the tissue. In order of frequency, the sites of stapleline bleeding are $40 \%$ from the gastric remnant staple line, $30 \%$ from the G-J staple line, and 30\% from the jejunojejunal staple line [28]. Interestingly, a meta-analysis comparing open versus laparoscopic RYGB noted that the frequency of bleeding was higher in the laparoscopic RYGB (LRYGB) series $(1.8 \%$ vs. $0.7 \%)$ [34]. Some hypotheses to explain this greater incidence of bleeding in the LRYGB in the minimally invasive surgery era are the overuse of chemoprophylaxis for deep vein thrombosis and the decreased in the practice of oversewing the staple lines. Two types of postoperative hemorrhage have been noted to occur following LRYGB: intraperitoneal or intraluminal [28]. The latter usually occurs as a late complication, while intraperitoneal bleeding occurs in the early postoperative course. As with any bleeding associated with surgery, early diagnosis is crucial. The clinical signs and symptoms are critical in determining the most appropriate steps for managing this life-threatening complication.

There are some potential methods for the prevention of staple-line bleeding. One method is to use a linear stapler with a shorter staple height. For example, using a white linear stapler load $(2.5 \mathrm{~mm})$ instead of a blue stapler load $(3.5 \mathrm{~mm})$ for the creation of the jejunojejunostomy, or a blue stapler load instead of a green stapler load $(4.8 \mathrm{~mm})$ for the creation of the gastric pouch [28]. The shorter staple height provides more compression of the tissues and hence results in better hemostasis. However, a shorter staple height does not completely prevent staple-line bleeding and it can increase the risk of leaking due to inadequate tissue approximation [28]. Another method for prevention of staple-line bleeding is the use of SLR. In a recent meta-analysis published by Shikora et al, the authors concluded that the use of SLR guaranteed a lower incidence of bleed events, particularly using bovine pericardium ( $1.28 \%$ vs. $3.13 \%$ without SLR vs. $3.10 \%$ using oversuture vs. 3.02\% using glycolide copolymer) [15].

Technical factors seem to be related to the incidence of

Table 2 Summary of staple-line complications after laparoscopic gastric bypass

\begin{tabular}{llll}
\hline & Incidence & Pathogenesis & Prevention \\
\hline Leak & $0.1-5.8 \%$ & $\begin{array}{l}\text { No differences related to the type of anastomosis (circular, } \\
\text { hand-sewn, linear) } \\
\text { Controversial effect of reinforcement (protective/worsening) }\end{array}$ & $\begin{array}{l}\text { Fibrin glue on G-J anastomosis; } \\
\text { Appropriate cartridge }\end{array}$ \\
Bleeding & $1.3-3.1 \%$ & $\begin{array}{l}\text { Patient-related factors: } \\
\text { liver disease, coagulopathy, hypertension, super-obesity, } \\
\text { revisional surgery } \\
\text { Surgeon-related factors: } \\
\text { No staple-line reinforcement, mechanical circular anastomosis }\end{array}$ & $\begin{array}{l}\text { Staple-line reinforcement (buttress, glue); } \\
\text { Linear or hand-sewn technique }\end{array}$ \\
& & $\begin{array}{l}\text { Local factors (ischemia, scar formation, and tension of the G-J } \\
\text { anastomosis); } \\
\text { G-J anastomosis technique; } \\
\text { Marginal ulcer }\end{array}$ & $\begin{array}{l}\text { G-J anastomosis }>21 \text { mm; linear or hand-sewn } \\
\text { technique; } \\
\text { Quit smoking and NSAID (marginal ulcer } \\
\text { prevention) }\end{array}$ \\
\hline
\end{tabular}


postoperative bleeding from the G-J anastomosis, as was demonstrated by Jiang et al, in a recently published metaanalysis evaluating the outcomes of HSA vs. circular CSA or linear LSA anastomosis [33]. Compared with CSA, HSA (OR 0.48; 95\%CI 0.31-0.74; $\mathrm{P}=0.001$; Fig. 4) was associated with significantly less postoperative bleeding. There was no significant difference between HSA and LSA (OR 1.27; 95\%CI 0.77-2.10; $\mathrm{P}=0.34$ ) [33]. A recent report by Ichter et al [35] showed that using an $\mathrm{EEA}^{\mathrm{Tm}}$ stapler reinforced with absorbable synthetic material yielded excellent results in terms of bleeding rate ( $0 \%$ in 125 cases) compared with the not-reinforced group. Fibrin sealant seems to be a valid option for reducing postoperative bleeding, as was reported by Silecchia et al in 2008 [36]. This multicenter randomized trial compared two groups of patients undergoing RYGBP, with or without fibrin sealant, and reported a $0 \%$ rate of bleeding from the G-J anastomosis in patients receiving fibrin sealant. The authors commented that the overall reintervention rate for early postoperative complications (anastomotic leak, internal hernia, and anastomotic bleeding) was significantly higher in the group that did not receive fibrin sealant $(\mathrm{P}=0.02)$. Recently, Ibele et al [32] found that $1.7 \%$ of patients in the sealant group experienced symptomatic postoperative bleeding requiring transfusion of $\geq 2$ units of blood, compared to $4.8 \%$ in the group that did not receive sealant $(\mathrm{P}=0.05)$, despite a high incidence of stricture in patients treated with fibrin sealant on the G-J anastomosis ( 11.3 vs. $5.8 \%$; $\mathrm{P}=0.04$ ).

In conclusion, staple-line bleeding after RYGB can be controlled with the use of SLR or fibrin sealant, while a circular G-J anastomosis carries a potential risk for intraluminal bleeding.

\section{Staple-line stenosis: pathogenesis and prevention}

Symptomatic narrowing and stenosis of the G-J anastomosis (incidence: 3-28\%) takes several weeks to a few months to develop and render the patient symptomatic [28]. It is typically followed by such symptoms as dysphagia, nausea, vomiting,

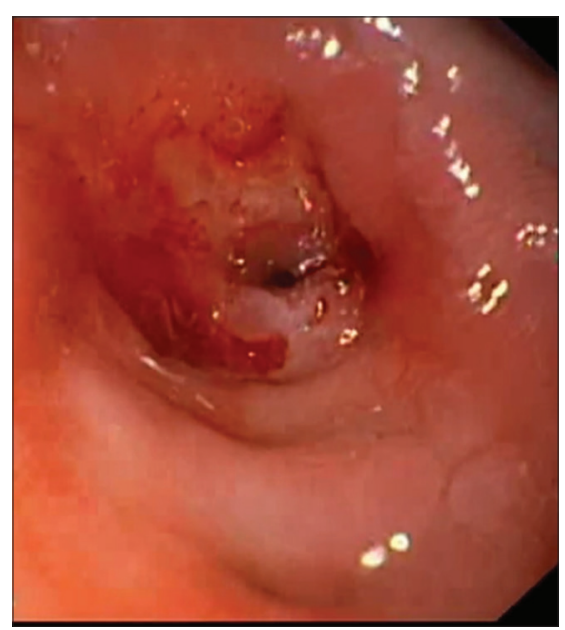

Figure 4 Gastric bypass: stenosis at gastrojejunal anastomosis and gastroesophageal reflux (Fig. 4). The etiology remains uncertain, but it seemingly depends on local factors (ischemia, scar formation, and tension of the anastomosis) and on the technique used to create the G-J anastomosis (i.e. hand-sewn, circular versus linear stapler, and size of stapler) [28,33]. For example, Nguyen et al reported a higher rate of stenoses using a $21 \mathrm{~mm}(26.8 \%)$ compared to a $25 \mathrm{~mm}(8.8 \%)$ circular stapler, with no effect on weight loss [37]. Another factor that has been shown to reduce the incidence of strictures is the handsewn construction of the gastrojejunostomy. Comparative studies of a circular mechanical anastomosis versus a handsewn anastomosis showed significantly greater stenosis rates in the circular stapler group ( $31 \%$ vs. $3 \%$ ) [30]. Linear staplers are also used for construction of the gastrojejunostomy, with the reported stricture rate being between $3.1 \%$ and $6.8 \%-$ lower than the rate quoted for circular staplers [30]. Despite the recently published data, a meta-analysis comparing the outcomes between hand-sewn vs. mechanical G-J anastomosis showed no difference in terms of postoperative stricture [33]. Interesting, applying fibrin sealant to the staple line, particularly to the anastomosis, seems to worsened the stricture rate, as recently reported by Ibele et al (11.3\% with vs. $4.8 \%$ without fibrin sealant $\mathrm{P}=0.04$ ) [32]. A central role in the pathogenesis of stenosis is played by the marginal ulcers, which have an incidence of between $0.6 \%$ and $16 \%$ [30]. Several previous studies attempted to define potential risk factors for the development of marginal ulcers, but it still remains a controversial topic $[30,38]$. There is currently no evidence for an association between the development of marginal ulceration after RYGB and the presence of Helicobacter pylori (H. pylori) infection [30]. H. pylori appears rather to cause an injury to the gastric mucosa preoperatively that potentiates the formation of marginal ulcer after gastric bypass. Therefore, $H$. pylori eradication is recommended prior to surgery. Other causes include smoking and alcohol consumption; use of nonsteroid anti-inflammatory drugs (NSAID); diabetes; excess acid exposure due to creation of a too-large gastric pouch, to dilatation of the gastric pouch over time, or to the presence

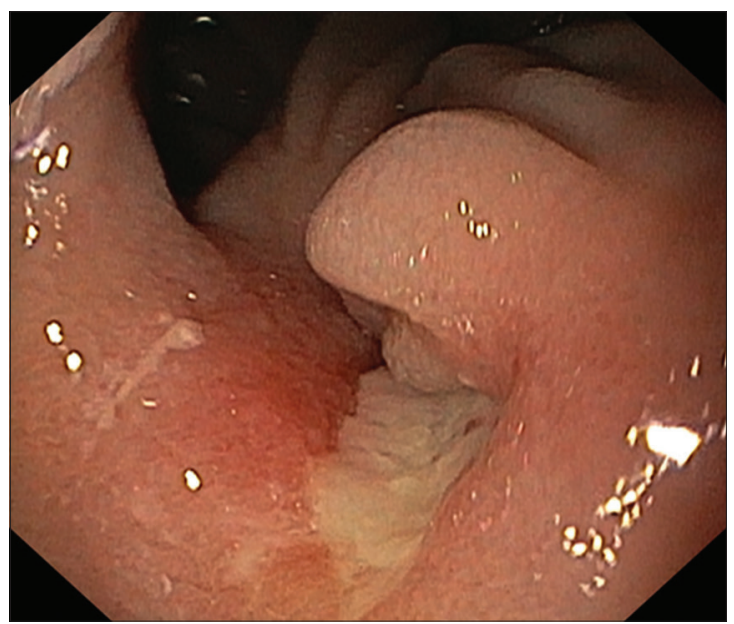

Figure 5 Recurrent marginal ulcer at gastrojejunal anastomosis after fibrin healing 
of a gastrogastric fistula; presence of foreign bodies, such as non-absorbable sutures or staples; and local factors, such as ischemia, or tension at the G-J anastomosis [30,38]. Even if marginal ulcers are multifactorial, the development of early marginal ulcer is more likely to be associated with local factors (ischemia, postoperative inflammation, stenosis, or foreign body) while late marginal ulcers are likely to be related to an increased acid exposition of the G-J anastomosis developing over time (Fig. 5) [30,38-39]. Zollinger-Ellison syndrome also has to be ruled out. In their review of 3430 procedures of RYGB, Felix et al identified 35 cases of perforation (1\%) with a median time to perforation of 18 months (range 3-70 months) [40]. Wendling et al have recently described the most delayed onset of perforated ulcer found in the literature, occurring 98 months after the original surgery [41]. In the study by Felix et al the incidence of smoking was significantly higher and the use of NSAID and steroids was common in patients presenting with a perforated ulcer [40].

In conclusion, stenosis has an incidence related to the technique (circular stapler vs. hand-sewn vs. linear), the G-J outlet diameter (smaller $=$ better weight loss result vs. high stenosis incidence) and the developing of a marginal ulcer (quitting smoking is always a good indication for patients who are candidates for RYGB). A summary of the complications is shown in Table 2.

\section{MGB: staple-line complications}

Laparoscopic MGB is an emerging surgical method that was first reported by Rutledge in 2001 [42]. Thousands of procedures have been performed worldwide [43-46], and the efficacy of MGB regarding weight loss and the improvement of comorbidities, as well as its safety, have been reported [43]. Based on a published systematic review, minor early postoperative complication rates ranged from 3.6-7.5\%, whereas major early postoperative complication rates ranged from $0-7 \%[47,48]$.

\section{Staple-line leak: pathogenesis and prevention}

The leakage incidence is reported to be between $0.8 \%$ and $1.6 \%$, with a rare report of a high percentage of $4.08 \%$ when performed as a revisional procedure $[47,48]$. A report of experience from over 1500 cases [45] cited a very low incidence $(0.1 \%)$, probably explained by the technical differences compared with RYGB: a long pouch that is not under pressure and a large anastomosis without tension. A major study was published in 2016 by Genser et al [49], evaluating the results of 2321 MGB procedures (62\% primary and 38\% revisional), focusing particularly on leak presentation after more than 8 -year experience. The authors reported an incidence of $1.5 \%$ : $57 \%$ from undetermined origin, $32 \%$ from the gastric tube and $11 \%$ from the G-J anastomosis. No leaks were found from the excluded stomach. The authors concluded that there was no statistical difference in terms of leak rate between revisional and primary procedures $(\mathrm{P}=0.21)$, or between one-stage and two-stage procedures [49].

In conclusion, the leak rate after MGB does not appear to be related to any particular technical factor, such as bougie size, choice of cartridge, and/or to patient-related factors such as revisional procedures and comorbidities, and the main prevention measures are similar to those indicated before for SG and RYGB, apart from SLR.

\section{Staple-line bleeding: pathogenesis and prevention}

Major bleeding (0.2-28.6\%) is the most commonly reported complication and in $0.3-0.58 \%$ of these cases reoperation and/or endoscopic/radiologic interventions are required [47,48]. The high percentage of bleeding reported by Copăescu et al may reflect the small sample size and represent only the initial experience of that center, given that the learning curve for MGB spans 30 cases [50]. Apart from the latter report, the maximum reported bleeding rate is $3.5 \%$. Because of the abundant blood supply in the gastric tube, bleeding after MGB can originate at one of three potential staple lines: the long gastric pouch, the excluded stomach and the G-J anastomosis. Intraluminal acute bleeding represents a rare complication (0.6\%) [48], particularly because the G-J anastomosis is performed with a linear stapler that allows immediate checking inside the lumen and treatment when necessary. The majority of the reported cases did not use SLR, and it is notable that the bleeding rate was comparable to, and sometimes lower than, those obtained using SLR in SG or RYGBP. This review, based on the available literature, cannot offer evidence from well-powered studies, but in our opinion the measures to prevent bleeding are the same as for SG and RYGBP: adequate devices (cartridges), adequate hemostatic control (intra-abdominal and systolic pressure), and the use of hemostatic devices based on personal choice.

\section{Staple-line stenosis: pathogenesis and prevention}

Anastomotic stricture after MGB occurs rarely, in a percentage between $0.1 \%$ and $1 \%$, and is rarely reported in the literature [48]. The presence of a 45-60 mm linear side-to-side anastomosis helps to avoid this complication, and the majority of surgeons use a similar technique [42-48], also because the weight loss related to the procedure is due more to a metabolic than to a restrictive effect. Carbajo, in a large series with longterm follow up (1200 patients, 70\% followed for 12 years), performed a G-J anastomosis of $2-2.5 \mathrm{~cm}$ in length, reporting 6 stomal stenoses $(0.5 \%)$ [46]. No case of stenosis related to the gastric pouch has been reported in the literature, there are reports of stenosis of the gastric reservoir [51].

In conclusion, despite the ample experience, it is hard to establish strong evidence and recommendations. The prevention of stenosis is based on the size of the G-J anastomosis (not less than $2.5 \mathrm{~cm}$ ), on respect for the distance from the greater curvature (not less than $2 \mathrm{~cm}$ to avoid gastric reservoir occlusion), and to symmetric, lateral traction of the stomach 
Table 3 Summary of staple-line complications after laparoscopic mini-gastric bypass

\begin{tabular}{llll}
\hline & Incidence & Pathogenesis & Prevention \\
\hline Leak & $0.8-1.6 \%$ & Not different from SG factors & $\begin{array}{l}\text { Not different from SG and RYGB factors } \\
\text { No evidence about use of reinforcement }\end{array}$ \\
Bleeding & $0.2-28.6 \%$ & $\begin{array}{l}\text { Not different from SG and RYGB } \\
\text { No evidence about use of } \\
\text { reinforcement }\end{array}$ & $\begin{array}{l}\text { Adequate devices (cartridges) } \\
\text { Adequate hemostatic control (intra-abdominal and systolic pressure) } \\
\text { Hemostatic devices based on personal choice } \\
\text { No evidence about use of reinforcement }\end{array}$ \\
Stenosis & $0.1-1 \%$ & $\begin{array}{l}\text { Asymmetric traction during } \\
\text { pouch creation; } \\
\text { Narrow G-J anastomosis }\end{array}$ & $\begin{array}{l}\text { Size of G-J anastomosis (not less than } 2.5 \mathrm{~cm} \text { ); } \\
\text { Adequate distance from the greater curvature (not less than 2 cm to avoid } \\
\text { gastric reservoir occlusion) } \\
\text { Symmetric, lateral traction of the stomach during vertical transection (as } \\
\text { previously reported for SG) }\end{array}$ \\
\hline
\end{tabular}

G-J, gastrojejunal; RYGB, Roux-en-Y gastric bypass; SG, sleeve gastrectomy

during vertical transection (as previously reported for SG). A summary of the complications is shown in Table 3.

\section{Concluding remarks}

This review shows how to prevent complications of the staple line and anastomoses during bariatric surgery, providing an evaluation of all factors that could potentially increase the rate. To reduce the complication rate it is mandatory to consider the patients' comorbidities and the following technical pitfalls: a. type of procedure (primary vs. revisional); b. use of a stapler with adequate cartridges; and c. reinforcement of the staple line/anastomoses (advantages not demonstrated for MGB). Respecting these basic rules, based on substantial experience, will help maintain low complication rates, compared with other abdominal surgeries, in these complex patients.

\section{References}

1. Angrisani L, Santonicola A, Iovino P, et al. Bariatric surgery and endoluminal procedures: IFSO Worldwide Survey 2014. Obes Surg 2017 [Epub ahead of print]. doi: 10.1007/s11695-017-2666.

2. Gagner M, Buchwald JN. Comparison of laparoscopic sleeve gastrectomy leak rates in four staple-line reinforcement options: a systematic review. Surg Obes Relat Dis 2014;10:713-723.

3. Jurowich C, Thalheimer A, Seyfried F, et al. Gastric leakage after sleeve gastrectomy - clinical presentation and therapeutic options. Langenbecks Arch Surg 2011;396:981-987

4. Iossa A, Abdelgawad M, Watkins BM, Silecchia G. Leaks after laparoscopic sleeve gastrectomy: overview of pathogenesis and risk factors. Langenbecks Arch Surg 2016;401:757-766.

5. Baker RS, Foote J, Kemmeter P, Brady R, Vroegop T, Serveld M. The science of stapling and leaks. Obes Surg 2004;14:1290-1298.

6. Huang R, Gagner M. A thickness calibration device is needed to determine staple height and avoid leaks in laparoscopic sleeve gastrectomy. Obes Surg 2015;25:2360-2367.

7. Rosenthal RJ, Diaz AA, Arvidsson D, et al; International Sleeve Gastrectomy Expert Panel. International Sleeve Gastrectomy Expert Panel Consensus Statement: best practice guidelines based on experience of $>12,000$ cases. Surg Obes Relat Dis 2012;8:8-19.

8. Natoudi M, Theodorou D, Papalois A, et al. Does tissue ischemia actually contribute to leak after sleeve gastrectomy? An experimental study. Obes Surg 2014;24:675-683.

9. Parikh M, Issa R, McCrillis A, Saunders JK, UdeWelcome A, Gagner M. Surgical strategies that may decrease leak after laparoscopic sleeve gastrectomy: a systematic review and meta-analysis of 9991 cases. Ann Surg 2013;257:231-237.

10. Berger ER, Clements RH, Morton JM, et al. The impact of different surgical techniques on outcomes in laparoscopic sleeve gastrectomies: the first report from the metabolic and bariatric surgery accreditation and quality improvement program (MBSAQIP). Ann Surg 2016;264:464-473.

11. Sanchez Santos R, Corcelles R, Vilallonga Puy R, et al. Prognostic factors of weight loss after sleeve gastrectomy: Multi centre study in Spain and Portugal. Cir Esp 2017;95:135-142.

12. ElGeidie A, ElHemaly M, Hamdy E, El Sorogy M, AbdelGawad M, GadElHakN. The effect of residual gastric antrum size on the outcome of laparoscopic sleeve gastrectomy: a prospective randomized trial. Surg Obes Relat Dis 2015;11:997-1003.

13. Obeidat F, Shanti H, Mismar A, Albsoul N, Al-Qudah M. The magnitude of antral resection in laparoscopic sleeve gastrectomy and its relationship to excess weight loss. Obes Surg 2015;25:1928-1932.

14. Noel P, Nedelcu M, Gagner M. Impact of the surgical experience on leak rate after laparoscopic sleeve gastrectomy. Obes Surg 2016;26:1782-1787.

15. Shikora SA, Mahoney CB. Clinical benefit of gastric staple line reinforcement (SLR) in gastrointestinal surgery: a meta-analysis. Obes Surg 2015;25:1133-1141.

16. Coskun H, Yardimci E. Effects and results of fibrin sealant use in 1000 laparoscopic sleeve gastrectomy cases. Surg Endosc 2017;31:2174-2179.

17. Sepúlveda M, Astorga C, Hermosilla JP, Alamo M. Staple line reinforcement in laparoscopic sleeve gastrectomy: experience in 1023 consecutive cases. Obes Surg 2017;27:1474-1480.

18. Albanopoulos K, Alevizos L, Linardoutsos D, et al. Routine abdominal drains after laparoscopic sleeve gastrectomy: a retrospective review of 353 patients. Obes Surg 2011;21:687-691.

19. Nedelcu M, Manos T, Gagner M, Eddbali I, Ahmed A, Noel P. Cost analysis of leak after sleeve gastrectomy. Surg Endosc 2017 [Epub ahead of print]. doi: 10.1007/s00464-017-5495-z.

20. Gagner M, Deitel M, Erickson AL, Crosby RD. Survey on laparoscopic sleeve gastrectomy (LSG) at the Fourth International Consensus Summit on Sleeve Gastrectomy. Obes Surg 2013;23:2013-2017.

21. Tønnesen H, Nielsen PR, Lauritzen JB, Møller AM. Smoking and 
alcohol intervention before surgery: evidence for best practice. $\mathrm{Br} J$ Anaesth 2009;102:297-306.

22. Loke YK, Trivedi AN, Singh S. Meta-analysis: gastrointestinal bleeding due to interaction between selective serotonin uptake inhibitors and non-steroidal anti-inflammatory drugs. Aliment Pharmacol Ther 2008;27:31-40.

23. Janik MR, Walędziak M, Brągoszewski J, Kwiatkowski A, Paśnik K. Prediction model for hemorrhagic complications after laparoscopic sleeve gastrectomy: development of SLEEVE BLEED calculator. Obes Surg 2017;27:968-972.

24. De Angelis F, Abdelgawad M, Rizzello M, Mattia C, Silecchia G. Perioperative hemorrhagic complications after laparoscopic sleeve gastrectomy: four-year experience of a bariatric center of excellence. Surg Endosc 2016 [Epub ahead of print]. doi: 10.1007/ s00464-016-5383-y

25. Agnihotri A, Barola S, Hill C, et al. An algorithmic approach to the management of gastric stenosis following laparoscopic sleeve gastrectomy. Obes Surg 2017 [Epub ahead of print]. doi: 10.1007/ s11695-017-2689-3.

26. Manos T, Nedelcu M, Cotirlet A, Eddbali I, Gagner M, Noel P. How to treat stenosis after sleeve gastrectomy? Surg Obes Relat Dis 2017;13:150-154.

27. Dapri G, Cadière GB, Himpens J. Laparoscopic seromyotomy for long stenosis after sleeve gastrectomy with or without duodenal switch. Obes Surg 2009;19:495-499.

28. Acquafresca PA, Palermo M, Rogula T, Duza GE, Serra E. Early surgical complications after gastric by-pass: a literature review. Arq Bras Cir Dig 2015;28:74-80.

29. Valli PV, Gubler C. Review article including treatment algorithm: endoscopic treatment of luminal complications after bariatric surgery. Clin Obes 2017;7:115-122.

30. Palermo M, Acquafresca PA, Rogula T, Duza GE, Serra E. Late surgical complications after gastric by-pass: a literature review. Arq Bras Cir Dig 2015;28:139-143.

31. Varban OA, Cassidy RB, Sheetz KH, et al; Michigan Bariatric Surgery Collaborative. Technique or technology? Evaluating leaks after gastric bypass. Surg Obes Relat Dis 2016;12:264-272.

32. Ibele AR, Bendewald FP, Mattar SG, McKenna DT. Incidence of gastrojejunostomy stricture in laparoscopic Roux-en-Y gastric bypass using an autologous fibrin sealant. Obes Surg 2014;24:1052-1056.

33. Jiang HP, Lin LL, Jiang X, Qiao HQ. Meta-analysis of hand-sewn versus mechanical gastrojejunal anastomosis during laparoscopic Roux-en-Y gastric bypass for morbid obesity. Int $J$ Surg 2016;32:150-157.

34. Rausa E, Bonavina L, Asti E, Gaeta M, Ricci C. Rate of death and complications in laparoscopic and open Roux-en-Y gastric bypass. A meta-analysis and meta-regression analysis on 69,494 patients. Obes Surg 2016;26:1956-1963.

35. Ichter ZA, Voeller L, Rivas H, Khoury H, Azagury D, Morton JM. Buttressing of the EEA stapler during gastrojejunal anastomosis decreases rate of bleeding-related complications for laparoscopic gastric bypass. Surg Obes Relat Dis 2017; 13: 802-806.

36. Silecchia G, Boru CE, Mouiel J, et al. The use of fibrin sealant to prevent major complications following laparoscopic gastric bypass: results of a multicenter, randomized trial. Surg Endosc 2008;22:2492-2497.

37. Nguyen NT, Stevens CM, Wolfe BM. Incidence and outcome of anastomotic stricture after laparoscopic gastric bypass. J Gastrointest Surg 2003;7:997-1003.

38. Azagury DE, Abu Dayyeh BK, Greenwalt IT, Thompson CC. Marginal ulceration after Roux-en-Y gastric bypass surgery: characteristics, risk factors, treatment, and outcomes. Endoscopy 2011;43:950-954.

39. Fringeli Y, Worreth M, Langer I. Gastrojejunal anastomosis complications and their management after laparoscopic Rouxen-Y gastric bypass. J Obes 2015;2015:698425.

40. Felix EL, Kettelle J, Mobley E, Swartz D. Perforated marginal ulcers after laparoscopic gastric bypass. Surg Endosc 2008;22:2128-2132.

41. Wendling MR, Linn JG, Keplinger KM, et al. Omental patch repair effectively treats perforated marginal ulcer following Roux-en-Y gastric bypass. Surg Endosc 2017;27:384-389.

42. Rutledge R. The mini-gastric bypass: experience with the first 1,274 cases. Obes Surg 2001;11:276-280.

43. Rutledge R, Walsh TR. Continued excellent results with the mini-gastric bypass: six-year study in 2,410 patients. Obes Surg 2005; 15:1304-1308.

44. Lessing Y, Pencovich N, Khatib M, Meron-Eldar S, Koriansky J, Abu-Abeid S. One-anastomosis gastric bypass: first 407 patients in 1 year. Obes Surg 2017 [Epub ahead of print]. doi: 10.1007/s11695017-2668-8

45. Taha O, Abdelaal M, Abozeid M, Askalany A, Alaa M. Outcomes of omega loop gastric bypass, 6-years experience of 1520 cases. Obes Surg 2017;27:1952-1960.

46. Carbajo MA, Luque-de-León E, Jiménez JM, Ortiz-de-Solórzano J, Pérez-Miranda M, Castro-Alija MJ. Laparoscopic one-anastomosis gastric bypass: technique, results, and long-term follow-up in 1200 patients. Obes Surg 2017;27:1153-1167.

47. Victorzon M. Single-anastomosis gastric bypass: better, faster, and safer? Scand J Surg 2015;104:48-53.

48. Georgiadou D, Sergentanis TN, Nixon A, Diamantis T, Tsigris C, Psaltopoulou T. Efficacy and safety of laparoscopic mini gastric bypass. A systematic review. Surg Obes Relat Dis 2014;10:984-991.

49. Genser L, Carandina S, Tabbara M, et al. Presentation and surgical management of leaks after mini-gastric bypass for morbid obesity. Surg Obes Relat Dis 2016;12:305-312.

50. Copăescu C, Munteanu R, Prala N, Turcu FM, Dragomirescu C. Laparoscopic mini gastric bypass for the treatment of morbid obesity. Initial experience. Chirurgia (Bucur) 2004;99:529-539.

51. Almulaifi AM, Ser KH, Lee WJ. Acute gastric remnant dilatation, a rare early complication of laparoscopic mini-gastric bypass. Asian J Endosc Surg 2014;7:185-187. 